\title{
INFLUÊNCIA DE LÂMINAS DE ÁGUA E ADUBAÇÃO MINERAL NA NUTRIÇÃO E PRODUTIVIDADE DE ARROZ DE TERRAS ALTAS ${ }^{(\mathbf{1})}$
}

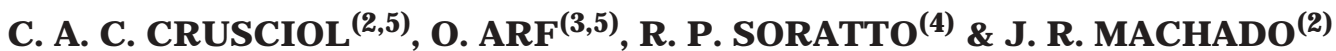

\begin{abstract}
RESUMO
Para recomendações de adubação mais racionais, é fundamental o conhecimento das exigências nutricionais da cultura do arroz, nos diversos sistemas de cultivo. Objetivando estudar a influência de lâminas de água na nutrição e exportação de nutrientes pelo arroz de terras altas, cultivar IAC 201, sob dois níveis de adubação, foram instalados experimentos em um Latossolo Vermelho distrófico, em Selvíria (MS), nos anos agrícolas de 1994/95 e 1995/96. 0 delineamento foi de blocos casualizados, com quatro repetições. Os tratamentos constituíram-se da preci pitação natural e de quatro lâmi nas de água fornecidas por aspersão. A lâmina $L_{2}$ foi baseada no coeficiente de cultura $(K c)$ do arroz de terras altas. As lâminas $L_{1}$ e $L_{3}$ foram definidas como 0,5 e 1,5 vez os $K c s$ utilizados em $L_{2}$, respectivamente, e na lâmina $L_{4}$ foi adotado $K c=1,95$ durante todo o ciclo da cultura. Em 1995/96, foram utilizados os mesmos tratamentos em parcelas subdivididas, sendo as subparcelas constituídas por duas doses de adubação (AD1 - 12 kg ha-1 de N, 90 de $\mathrm{P}_{2} \mathrm{O}_{5}$ e 30 de $\mathrm{K}_{2} \mathrm{O}$, e AD2 - 24 kg ha-1 de N, 180 de $\mathrm{P}_{2} \mathrm{O}_{5}$ e 60 de $\mathrm{K}_{2} \mathrm{O}$ ). A menor disponibilidade de água durante a fase vegetativa e reprodutiva proporcionou redução na produção de matéria seca, nos teores e quantidades de nutrientes acumuladas na parte aérea. $\mathbf{O}$ sistema irrigado por aspersão, independentemente da lâmina utilizada, proporcionou maior produtividade de grãos e exportação de nutrientes. Em solos com teores adequados de nutrientes para o sistema de sequei ro, não há resposta ao aumento da adubação mineral pelo arroz no sistema irrigado por aspersão, apesar da maior extração de nutrientes.
\end{abstract}

Termos de indexação: Oryza sativa L., irrigação por aspersão, macronutrientes, exportação de nutrientes.

\footnotetext{
(1) Parte da Tese de Doutorado do primeiro autor, apresentada à Faculdade de Ciências Agronômicas - FCA/UNESP. Botucatu (SP). Projeto financiado pela FAPESP. Recebido para publicação em novembro de 2002 e aprovado em maio de 2003.

(2) Professor Adjunto do Departamento de Produção Vegetal, Faculdade de Ciências Agronômicas - FCA/UNESP. Fazenda Experimental Lageado s/n, CEP 18603-970 Botucatu (SP). E-mail: crusciol @fca.unesp.br

(3) Professor Titular do Departamento de Fitotecnia, Tecnol ogia de Alimentos e Sócio-E conomia, Faculdade de Engenharia, Universidade Estadual Paulista - FEIS/UNESP. Caixa Postal 31, CEP 15385-000 Il ha Solteira (SP). E-mail: arf@agr.feis.unesp.br

(4) Doutorando do Curso de Agricultura, Faculdade de Ciências Agronômicas, UNESP. E-mail: soratto@fca.unesp.br

${ }^{(5)}$ Bolsista do CNPq.
} 


\title{
SUMMARY: INFLUENCE OF WATER LEVELS AND MINERAL FERTILIZA- TION ON NUTRITION AND YIELD OF UPLAND RICE
}

\begin{abstract}
In order to achievemoresound fertilizer recommendations, knowledgeabout nutritional requirements of rice in different growing systems is fundamental. The objective of this paper was to evaluate the effects of water levels on nutrition and nutrient exportation by upland rice (cultivar IAC 201) under two levels of mineral fertilizer. Experiments were conducted in thegrowing seasons of 1994/ 95 and 1995/ 96 on a Typic Haplustox, in Se víria, State of Mato Grosso do Sul, Brazil. The experimental design was of randomized blocks, with four replications. The treatments werefive water levels: natural rain and four water levels provided by sprinkler irrigation. Water leve $2\left(L_{2}\right)$ was based on the crop coefficient $(K c)$ for upland rice. $L_{1}$ and $L_{3}$ were then defined as 0.5 and 1.5 times the Kcs used in $L_{2}$, respectively. For water level $4\left(\mathrm{~L}_{4}\right), \mathrm{Kc}=1.95$ was used during the entire plant cycle. The sametreatments wereapplied in 1995/ 96 in a split-pl ot scheme. Thesubplots consisted in two NPK-fertilization levels (AD1 - $12 \mathrm{~kg} \mathrm{ha}^{-1}$ of N, 90 of $\mathrm{P}_{2} \mathrm{O}_{5}$, and 30 of $\mathrm{K}_{2} \mathrm{O}$; and AD2 $24 \mathrm{~kg} \mathrm{ha}^{-1}$ of $\mathrm{N}, 180$ of $\mathrm{P}_{2} \mathrm{O}_{5}$, and 60 of $\mathrm{K}_{2} \mathrm{O}$ ). Low water availability during the vegetative and reproductive phases decreased the dry matter yield, nutrient contents, and nutrient uptake. Sprinkler irrigati on increased grain yield and nutrient exportation, independent of the water level. In soils with appropriatenutrient levels for thedryland system, theirrigated rice did not respond to increased mineral fertilization, despite thelarger nutrient uptake.
\end{abstract}

Index terms: Oryza sativa L., sprinkler irrigation, macronutrient, nutrient exportation.

\section{NTRODUÇÃO}

A absorção adequada de nutrientes pelas plantas de arroz está condicionada a processos fisiológicos inerentes aos cultivares utilizados (F ageria et al., 1995) e à sua adaptabilidade à disponibilidade de água. Assim, o conhecimento das exigências nutricionais da cultura, nas diversas situações de cultivo, pode contribuir para o estabelecimento de fórmulas e recomendações de adubação mais racionais (Giudice et al., 1983; Barbosa Filho, 1987).

A maioria das lavouras de arroz de terras altas, no Brasil, está localizada na região dos cerrados. Essa região écaracterizada pelo predomínio de solos com baixa fertilidade natural e elevada saturação por al umínio, além da ocorrência de períodos curtos de estiagem, denominados veranicos, que provocam deficiência hídrica à cultura, afetando a absorção de nutrientes (Ponnamperuma, 1975), principal mente de fósforo e, em menor grau, de potássio, os quais chegam à superfície da raiz pel o processo de difusão (Stone, 1985; Tanguilig et al., 1987). Tais fatos reduzem a produção de matéria seca total (Carval ho J únior, 1987; Tanguilig et al., 1987; Prasertsak \& Fukai, 1997), causam decréscimo da produtividade do arroz no sistema de sequeiro (Stone, 1985; Crusciol et al., 1999) e na exportação de macro e micronutrientes (CarvalhoJ únior, 1987).

Para solucionar o problema da deficiência hídrica provocada pel os veranicos, a irrigação por aspersão tem-se apresentado como alternativa eficiente, proporcionando uma melhor nutrição e, conseqüentemente, maior produtividade da cultura do arroz de terras altas (Crusciol et al., 2000). Com oaumento da produtividade degrãos, há tambémuma mai or exportação denutrientes da área. No entanto, existem poucas informações sobre as exigências nutricionais do arroz de terras altas no sistema irrigado por aspersão, já quea mai oria dos estudos se refereaos sistemas irrigados por inundação esequeiro.

Assim, as recomendações de adubação para a cultura do arroz no estado de São Paulo constantes no Bol etim 100 (Raij et al., 1996) são referentes ao sistema de sequeiro e irrigado por inundação, não havendo recomendações para o sistema irrigado por aspersão, como existem para outras culturas, notadamente o trigo.

Por outro lado, é importante ressaltar que uma adubação adequada pode aumentar a produtividade do arroz de terras al tas em sol os decerrado, se outros fatores não forem limitantes. Com a eliminação do risco de deficiência hídrica, por meio da irrigação por aspersão, torna-se viável utilizar um nível mais el evado de adubação em rel ação ao usado no sistema de sequeiro (Santos et al., 1982). No entanto, não há recomendações de calagem e adubação para cultivares mel horados, sob irrigação por aspersão.

O presente trabalho objetivou verificar o efeito de lâminas de água aplicadas por aspersão sobre a produção de matéria seca, nutrição e exportação de nutrientes pelo arroz, cv. IAC 201, de terras altas, cultivado sob duas doses de adubação mineral .

\section{MATERIAL E MÉTODOS}

O trabalho foi realizado em área experimental pertencente à Faculdade de Engenharia, UNESP, Campus de Il ha Solteira, localizada no município 
de Selvíria (MS), situado a 51 22 ' de longitude Oestee 20 ○22 ' delatitudeSul, com altitudede 335 m, nos anos agrícolas de 1994/95 e 1995/96. O solo do local é do tipo Latossolo Vermelho distrófico típico argiloso (EMBRAPA, 1999). As características químicas do solo foram determinadas antes da instal ação do experimento, segundo método proposto por Raij \& Quaggio (1983) (Quadro 1). Os valores médios anuais para precipitação, temperatura e umidade relativa são de $1.370 \mathrm{~mm}, 23,5^{\circ} \mathrm{C}$ e 70 $80 \%$, respectivamente.

O delineamento utilizado, nos dois experimentos, foi o de blocos ao acaso, com quatro repetições. O experimento, realizado no ano agrícola de 1994/95, foi constituído de cinco lâminas de água, uma das quais foi a precipitação pluvial natural, ou seja, cultivo sob condições de sequeiro, e as demais, fornecidas por meio de irrigação por aspersão e definidas com base no coeficiente de cultura (Kc) (Quadro 2). Os Kcs apresentados por Reichardt (1987) para a cultura do arroz de terras altas, com al gumas adaptações, resultaram na lâmina $2\left(\mathrm{~L}_{2}\right)$. As lâminas 1 e $3\left(L_{1}\right.$ e $\left.L_{3}\right)$ foram definidas com base na utilização de 0,5 e 1,5 vez os valores dos $K$ cs da $L_{2}$, respectivamente. J á na lâmina $4\left(L_{4}\right)$, foi utilizado o mai or Kc da lâmina $3(\mathrm{Kc}=1,95)$, durante todo o período de irrigação. No ano 1995/96, o experimento utilizou parcelas subdivididas. As parcelas com as cinco lâminas de água estudadas no ano agrícola anterior (Quadro 2) foram divididas em subparcelas consistindo de duas doses de adubação: ADl (12 kg ha-1 de N, 90 de $\mathrm{P}_{2} \mathrm{O}_{5}$ e 30 de $\mathrm{K}_{2} \mathrm{O}$ ) - quantidades determinadas de acordo com a análise química do solo (Quadro 1) e recomendação de Raij et al. (1985), e AD2 (24 kg ha-1 de N, 180 de $\mathrm{P}_{2} \mathrm{O}_{5}$ e 60 de $\mathrm{K}_{2} \mathrm{O}$ ) - o dobro da adubação recomendada.

Cada unidade experimental continha seis linhas de $6 \mathrm{~m}$ de comprimento espaçadas em $0,40 \mathrm{~m}$. Foram consideradas, como área útil, as quatro fileiras centrais, sendo $0,50 \mathrm{~m}$ da extremidade de cada fileira de plantas e as duas fileiras externas consideradas como bordadura.

A capacidade de água disponível (CAD), em $\mathrm{mm}$, foi calculada segundo a expressão: CAD = [(CC-PMP)/100].d.h, em que CC é a capacidade de campo (\%); PMP é o ponto de murcha permanente (\%); d é a densidade do solo $\left(1.250 \mathrm{~kg} \mathrm{~m}^{-3}\right) ; \mathrm{h}$ é a profundidade efetiva do sistema radicular $(0,20 \mathrm{~m})$. Assim, a CAD do solo utilizada ficou estabelecida em $14,80 \mathrm{~mm}$.

Quadro 1. Características químicas do solo na profundidade de $0-20 \mathrm{~cm}$

\begin{tabular}{|c|c|c|c|c|c|c|c|c|c|c|}
\hline Ano & M.O. & $\mathrm{pH} \mathrm{CaCl} 2$ & P resina & $\mathbf{K}$ & $\mathrm{Ca}$ & Mg & $\mathbf{H}+\mathbf{A l}$ & SB & СТC & $\mathbf{v}$ \\
\hline & $\mathrm{g} \mathrm{kg}^{-1}$ & & $\mathrm{mg} \mathrm{dm}^{-3}$ & 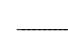 & 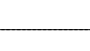 & $-\mathrm{mm}$ & $\mathrm{dm}^{-3}$ & 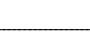 & - & $\%$ \\
\hline $\begin{array}{l}1994 / 95 \\
1995 / 96\end{array}$ & $\begin{array}{l}26 \\
23\end{array}$ & $\begin{array}{l}5,4 \\
5,1\end{array}$ & $\begin{array}{l}24 \\
26\end{array}$ & $\begin{array}{l}1,3 \\
1,9\end{array}$ & $\begin{array}{l}24,0 \\
28,0\end{array}$ & $\begin{array}{r}15,2 \\
8,0\end{array}$ & $\begin{array}{l}29,2 \\
28,0\end{array}$ & $\begin{array}{l}40,5 \\
37,9\end{array}$ & $\begin{array}{l}69,7 \\
65,9\end{array}$ & $\begin{array}{l}58 \\
58\end{array}$ \\
\hline
\end{tabular}

Quadro 2. Lâminas de água e respectivos valores de Kc (Coeficiente de cultura) utilizados para o cálculo da reposição de água nas diversas fases de desenvolvimento da cultura do arroz de terras altas

\begin{tabular}{|c|c|c|c|c|c|c|c|}
\hline \multirow{3}{*}{ Tratamento } & \multicolumn{2}{|c|}{ DF } & \multicolumn{5}{|c|}{$\mathbf{F}$} \\
\hline & \multirow{2}{*}{$\begin{array}{c}\text { Fase vegetativa } \\
\mathrm{P}^{(2)}\end{array}$} & \multicolumn{3}{|c|}{ Fase reprodutiva } & \multicolumn{3}{|c|}{ Fase de maturação } \\
\hline & & $\mathbf{P} 2$ & $\mathbf{P} 3$ & P4 & P 5 & P 6 & \\
\hline & \multicolumn{2}{|c|}{-30} & \multicolumn{2}{|c|}{-11} & \multicolumn{2}{|c|}{+5} & \multirow[t]{2}{*}{+12} \\
\hline & \multicolumn{6}{|c|}{ - Valor de Kc } & \\
\hline Lâmina 1 (L 1) & 0,20 & 0,35 & 0,50 & 0,65 & 0,50 & 0,35 & \\
\hline Lâmina 2 (L 2) & 0,40 & 0,70 & 1,00 & 1,30 & 1,00 & 0,70 & \\
\hline Lâmina 3 (L 3) & 0,60 & 1,05 & 1,50 & 1,95 & 1,50 & 1,05 & \\
\hline Lâmina 4 (L 4) & 1,95 & 1,95 & 1,95 & 1,95 & 1,95 & 1,95 & \\
\hline
\end{tabular}

(1) E- Emergência; DF - Diferenciação floral; F - Florescimento. ${ }^{(2)}$ Período (em dias) de utilização dos valores de coeficientes de cultura em relação ao florescimento. P1: período compreendido entre a emergência e 30 dias antes do florescimento; P2: período entre 30 e 19 dias antes do florescimento; P3: período entre 19 e 11 dias antes do florescimento; P4: período entre 11 e 3 dias do florescimento; P5: período entre 3 dias antes e 5 dias após o florescimento; P6: período entre 5 e 12 dias após o florescimento. 
As irrigações foram realizadas quando a evapotranspiração máxima (ETm) da cultura atingiu $8,25 \mathrm{~mm}$, ou seja, 45 \% da CAD. A evapotranspiração máxima da cultura em $\mathrm{mm}^{\mathrm{di}} \mathrm{a}^{-1}$ (ETm) foi determinada pela expressão: $\mathrm{ETm}=\mathrm{Kc}$. Eto, em que $\mathrm{ETo}=$ evapotranspiração de referência $\left(\mathrm{mm} \mathrm{dia}^{-1}\right)$ e $\mathrm{Kc}=$ coeficiente de cultura. A evapotranspiração de referência (ETo) foi determinada pela expressão ETo $=\mathrm{Kp}$.ECA, em que ECA = evaporação do tanque classe $A\left(\mathrm{~mm} \mathrm{dia}^{-1}\right)$ e $\mathrm{Kp}=$ coeficiente do tanque classe A.

A evaporação de água foi obtida diariamente de um Tanque Classe $A$. O coeficiente do Tanque Classe A (Kp) utilizado foi o proposto por Doorenbos \& Pruitt (1976), o qual depende da área circundante, velocidade do vento e umidade relativa do ar. As irrigações foram realizadas por um sistema de aspersão convencional fixo, com precipitação de 3,3 $\mathrm{mm}_{\text {hora }}{ }^{-1}$.

Durante o experimento, foram determinadas, diariamente, a temperatura mínima e máxima do ar no Posto Meteorológico da Fazenda de Ensino e Pesquisa da Faculdade de Engenharia de IIha Solteira - UNESP, distante, aproximadamente, $500 \mathrm{~m}$ dolocal. A preci pitação pluvial foi determinada em um pluviômetro Ville de Paris instaladona área experimental. Todos os dados dos elementos climáticos estão contidos na figura 1.

O cultivar IAC 201, proveniente do Instituto Agronômico de Campinas, é a denominação comercial da linhagem de arroz (Oryza sativa L.) de sequeiro obtida do cruzamento entre o cultivar IAC 165, de ampla adaptação, e o cultivar Labelle, de excel ente qual idade de grão, real izado em Campinas (SP), no ano agrícola 1977/78. Apresenta como características principais: porte médio $(100 \mathrm{~cm})$, ciclo precoce (110-120 dias), com 78 a 90 dias da emergência ao florescimento (São Paulo, 1992).

O solo foi preparado por meio de uma aração e duas gradagens: a primeira gradagem foi efetuada logo após a aração ea segunda, antes da semeadura. No ano agrícola de 1994/95, a adubação constou da aplicação, nos sulcos de semeadura, de $12 \mathrm{~kg} \mathrm{ha}^{-1}$ de $\mathrm{N}, 90$ de $\mathrm{P}_{2} \mathrm{O}_{5}$ e 30 de $\mathrm{K}_{2} \mathrm{O}$. No ano agrícola de 1995/96, a adubação NPK tornou-se parte dos tratamentos, conforme descrito anteriormente. Também foram aplicados, nos dois anos, $40 \mathrm{~kg} \mathrm{ha}^{-1}$ de FTE BR-12 como fonte de micronutrientes $(\mathrm{B}=$ $1,3 \%$; $\mathrm{Cu}=0,30 \% ; \mathrm{Fe}=3,0 \% ; \mathrm{Mn}=2,0 \%$; $\mathrm{Mo}=$ $0,1 \% ; \mathrm{Zn}=9,0 \%)$.

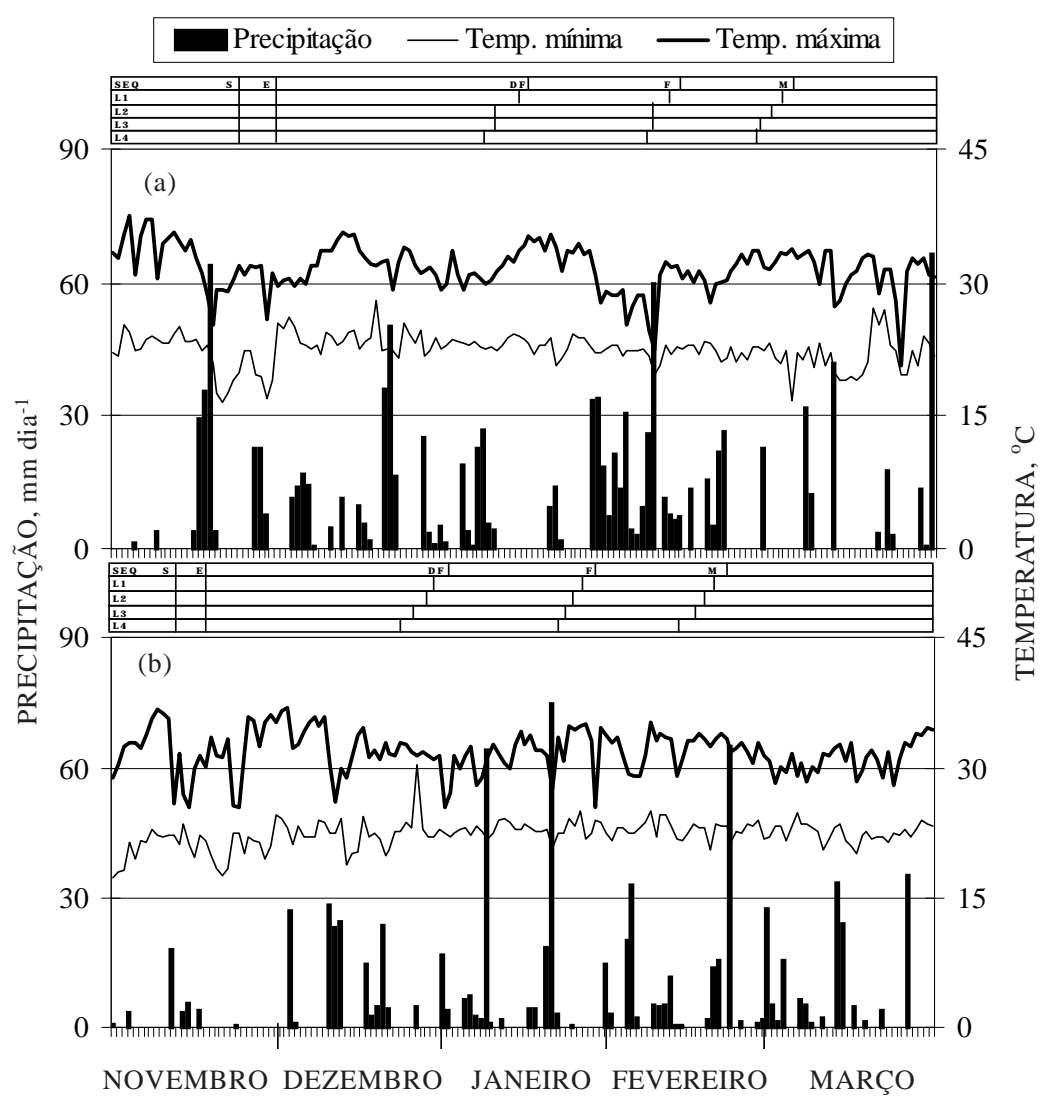

Figura 1. Preci pitação pluvial, temperatura máxi ma e mínima, obtidas na área do experimento, durante o período de novembro a março, nos anos agrícolas de 1994/95 (a) e 1995/96 (b). Selvíria (MS). S Semeadura; E - E mergência; DF - Diferenciação floral; F - Florescimento; M - Maturação. 
As semeaduras das safras 1994/95 e 1995/96 foram realizadas em 24/11/94 e 13/11/95, respectivamente, utilizando a densidade de 100 sementes viáveis por metro quadrado. J unto com as sementes, foi aplicado $1,5 \mathrm{~kg} \mathrm{ha}^{-1}$ de carbofuran $5 \mathrm{G}$ (i.a.), visando ao controle de cupins (Synterms molestus, Procorniterms striatus e Cornitermes lespesii) e da lagarta elasmo (Elasmopalpus lignosellus). A emergência das plântulas ocorreu em 02/12/94 e 21/11/95, respectivamente. O ciclo e a quantidade de água recebida pela cultura do arroz nos diferentes tratamentos estão apresentados no quadro 3.

O controle de plantas daninhas foi efetuado por meio da aplicação do herbicida oxadiazon (1 kg ha-1 de i.a.), em pré-emergência, um dia após a semeadura, e2,4D (670 g ha-1 de i.a.) aos 35 dias da emergência. A adubação de cobertura foi realizada na época de perfilhamento das plantas, com aplicação de $30 \mathrm{~kg} \mathrm{ha}^{-1}$ de N na forma de uréia.

Foi realizada uma coleta de plantas, em 2,0 m de fileira, no momento em que $50 \%$ das panículas de cada unidade experimental atingiram 0 florescimento. O material coletado foi seco em estufa a $60^{\circ} \mathrm{C}$ e, em seguida, foram feitas a pesagem e a transformação dos dados em $\mathrm{kg}_{\text {ha-1 }}$ de matéria seca. Posteriormente, realizou-se a moagem do material colhido no qual foram determinados, pela análise química, os teores de $\mathrm{N}, \mathrm{P}, \mathrm{K}, \mathrm{Ca}, \mathrm{Mg}, \mathrm{S}$, segundo método descrito por Bataglia et al. (1983). De posse desses resultados, foram estimadas as quantidades absorvidas desses nutrientes por área, de acordo com os tratamentos.

A colheita do arroz foi efetuada manualmente, quando os grãos dos $2 / 3$ superiores de $50 \%$ das panículas apresentaram-se duros e os do seu terço inferior, semiduros. A seguir, foram feitas a trilha manual, a secagem à sombra ea limpeza do material, separando-se a pal ha e os grãos chochos com auxílio deuma peneira, por abanação manual. Em seguida, determinou-se o peso dos grãos colhidos e foi calculada a produtividade de grãos por hectare (13\% base úmida). Dos grãos colhidos, foram retiradas amostras de $100 \mathrm{~g}$ de grãos com casca que foram secas em estufa a $60^{\circ} \mathrm{C}$, moídos e determinados, por meio de análise química, os teores de $\mathrm{N}, \mathrm{P}, \mathrm{K}, \mathrm{Ca}$, Mg e S, segundo método descrito por Bataglia et al. (1983). De posse desses resultados, foram estimadas as quantidades exportadas desses nutrientes por área, pelos grãos com casca. Os dados foram submetidos à análise de variância e as médias comparadas pelo teste de Tukey.

\section{RESULTADOS E DISCUSSÃO}

No primeiro ano de experimento, a produção de matéria seca não foi influenciada significativamente pel os tratamentos (Quadro 4). Já, no segundo ano, a produção de matéria seca foi significativamente influenciada apenas pelas lâminas de água. A lâmina $L_{3}$ proporcionou a maior produção $\left(7.732 \mathrm{~kg} \mathrm{ha}^{-1}\right)$, diferindo da lâmina $L_{1}$ e do tratamento desequeiro. Os veranicos, ocorridos até o florescimento (Figura 1), proporcionaram provavelmente deficiências hídricas na cultura, reduzindo a produção de matéria seca nos tratamentos com menor disponibilidade de água (sequeiro e $L_{1}$ ). Resultados semelhantes foram obtidos por Stone et al. (1984), Carvalho J únior (1987).

A adubação NPK não influiu na produção de matéria seca, o que pode ser explicado pelos níveis adequados de nutrientes no solo, principalmente de fósforo e potássio (Quadro 1).

Quanto aos teores de nutrientes na matéria seca da planta de arroz no florescimento, não houve diferenças significativas entre os tratamentos no primeiro ano de cultivo (Quadro 4). No segundo ano,

Quadro 3. Ciclo da cultura e distribuição das lâminas de água nos diferentes tratamentos durante o desenvolvimento da cultura

\begin{tabular}{lccccc}
\hline & \multicolumn{5}{c}{ Tratamento } \\
\cline { 2 - 6 } & Sequeiro & $\mathbf{L}_{\mathbf{1}}$ & $\mathbf{L}_{\mathbf{2}}$ & $\mathbf{L}_{\mathbf{3}}$ & $\mathbf{L}_{\mathbf{4}}$ \\
\hline & & & $1994 / 95$ & \\
Ciclo (dias) & 96 & 95 & 92 & 90 & 87 \\
Irrigação (mm) & - & 37,4 & 73,9 & 133,2 & 318,3 \\
Totais de água (mm) & 813,0 & 842,5 & 849,5 & 908,8 & 1093,9 \\
& & & $1995 / 96$ & & \\
Ciclo (dias) & 97 & 94 & 91 & 87 & 84 \\
Irrigação (mm) & - & 28,9 & 100,0 & 183,9 & 381,7 \\
Totais de água (mm) & 598,8 & 626,7 & 687,8 & 760,5 & 951,5 \\
\hline
\end{tabular}


Quadro 4. Matéria seca da parte aérea, teores e quantidades de macronutrientes absorvidos pelo arroz, Cv. IAC 201, de acordo com diferentes lâminas de água e doses de adubação mineral. Selvíria (MS)

\begin{tabular}{|c|c|c|c|c|c|c|c|c|c|c|c|c|c|}
\hline \multirow{2}{*}{ Tratamento } & \multirow{2}{*}{$\begin{array}{c}\text { Matéria } \\
\text { seca }\end{array}$} & \multicolumn{6}{|c|}{ Teor de nutriente na parte aérea } & \multicolumn{6}{|c|}{ Quantidade extraída de nutrientes } \\
\hline & & $\mathbf{N}$ & $\mathbf{P}$ & $\mathbf{K}$ & $\mathrm{Ca}$ & Mg & $\mathbf{S}$ & $\mathbf{N}$ & $\mathbf{P}$ & $\mathbf{K}$ & $\mathbf{C a}$ & Mg & $\mathbf{S}$ \\
\hline & \multirow[t]{2}{*}{$\mathrm{kg} \mathrm{ha}^{-1}$} & & & - & $\mathrm{kg}^{-1}$ & & - & & & - & -1 & & \\
\hline & & \multicolumn{12}{|c|}{ 1994/95 } \\
\hline $\begin{array}{l}\text { Sequeiro } \\
L_{1} \\
L_{2} \\
L_{3} \\
L_{4}\end{array}$ & $\begin{array}{l}4.366 \\
7.045 \\
5.956 \\
7.400 \\
6.724\end{array}$ & $\begin{array}{l}15,2 \\
14,8 \\
15,6 \\
15,4 \\
14,9\end{array}$ & $\begin{array}{l}2,30 \\
2,48 \\
2,25 \\
2,12 \\
2,24\end{array}$ & $\begin{array}{l}11,3 \\
13,5 \\
10,5 \\
12,0 \\
13,6\end{array}$ & $\begin{array}{l}3,80 \\
3,90 \\
3,70 \\
3,70 \\
3,40\end{array}$ & $\begin{array}{l}2,40 \\
2,34 \\
2,40 \\
2,64 \\
3,18\end{array}$ & $\begin{array}{l}1,17 \\
1,24 \\
1,19 \\
1,30 \\
1,19\end{array}$ & $\begin{array}{r}65 \\
101 \\
93 \\
113 \\
100\end{array}$ & $\begin{array}{r}7,2 \\
16,5 \\
13,4 \\
15,6 \\
14,8\end{array}$ & $\begin{array}{l}47 \\
93 \\
62 \\
85 \\
88\end{array}$ & $\begin{array}{l}16 \\
26 \\
22 \\
27 \\
22\end{array}$ & $\begin{array}{l}10 \\
16 \\
14 \\
19 \\
21\end{array}$ & $\begin{array}{l}4,8 \\
8,5 \\
7,1 \\
9,4 \\
7,9\end{array}$ \\
\hline \multirow[t]{2}{*}{ C.V. (\%) } & 34,29 & 15,77 & 24,80 & 22,26 & 18,33 & 33,67 & 14,59 & 22,07 & 21,31 & 22,86 & 16,42 & 29,19 & 16,66 \\
\hline & & \multicolumn{12}{|c|}{ 1995/96 } \\
\hline $\begin{array}{l}\text { Sequeiro } \\
\mathrm{L}_{1} \\
\mathrm{~L}_{2} \\
\mathrm{~L}_{3} \\
\mathrm{~L}_{4}\end{array}$ & $\begin{array}{l}4.462 \mathrm{~b} \\
5.073 \mathrm{~b} \\
6.322 \mathrm{ab} \\
7.732 \mathrm{a} \\
5.483 \mathrm{ab}\end{array}$ & $\begin{array}{l}13,2 \\
12,0 \\
13,7 \\
15,2 \\
13,5\end{array}$ & $\begin{array}{l}1,41 \\
1,48 \\
1,46 \\
1,46 \\
1,63\end{array}$ & $\begin{array}{r}10,3 \\
9,9 \\
10,6 \\
11,0 \\
10,7\end{array}$ & $\begin{array}{r}4,08 \mathrm{~b} \\
4,00 \mathrm{~b} \\
13,22 \mathrm{a} \\
7,26 \mathrm{ab} \\
6,04 \mathrm{ab}\end{array}$ & $\begin{array}{l}1,96 \mathrm{~b} \\
1,97 \mathrm{~b} \\
4,84 \mathrm{a} \\
3,43 \mathrm{ab} \\
2,49 \mathrm{~b}\end{array}$ & $\begin{array}{l}1,15 \mathrm{a} \\
1,05 \mathrm{ab} \\
1,10 \mathrm{ab} \\
0,97 \mathrm{~b} \\
1,01 \mathrm{ab}\end{array}$ & $\begin{array}{l}58 \mathrm{~b} \\
60 \mathrm{~b} \\
86 \mathrm{ab} \\
118 \mathrm{a} \\
73 \mathrm{ab}\end{array}$ & $\begin{array}{c}6,1 \mathrm{~b} \\
7,5 \mathrm{ab} \\
9,1 \mathrm{ab} \\
11,2 \mathrm{a} \\
8,8 \mathrm{ab}\end{array}$ & $\begin{array}{l}45 \\
50 \\
66 \\
85 \\
58\end{array}$ & $\begin{array}{l}18 b \\
20 a b \\
80 a \\
59 a b \\
33 a b\end{array}$ & $\begin{array}{c}8,6 \mathrm{c} \\
9,9 \mathrm{bc} \\
30,0 \mathrm{a} \\
26,4 \mathrm{ab} \\
13,5 \mathrm{abc}\end{array}$ & $\begin{array}{l}5,0 \mathrm{~b} \\
5,2 \mathrm{~b} \\
6,8 \mathrm{ab} \\
7,5 \mathrm{a} \\
5,5 \mathrm{ab}\end{array}$ \\
\hline C.V. (\%) & 17,52 & 6,11 & 3,62 & 10,15 & 22,34 & 14,43 & 17,52 & 12,96 & 8,44 & 15,18 & 28,81 & 19,62 & 7,51 \\
\hline $\begin{array}{l}\text { AD1 } \\
\text { AD2 }\end{array}$ & $\begin{array}{l}5.641 \\
5.938\end{array}$ & $\begin{array}{l}13,8 \\
13,2\end{array}$ & $\begin{array}{l}1,49 \\
1,49\end{array}$ & $\begin{array}{l}10,8 \\
10,2\end{array}$ & $\begin{array}{l}6,98 \\
6,20\end{array}$ & $\begin{array}{l}2,94 \\
2,78\end{array}$ & $\begin{array}{l}1,05 \\
1,06\end{array}$ & $\begin{array}{l}77 \\
78\end{array}$ & $\begin{array}{l}8,2 \\
8,7\end{array}$ & $\begin{array}{l}59 \\
60\end{array}$ & $\begin{array}{l}41 \\
36\end{array}$ & $\begin{array}{l}16,9 \\
16,3\end{array}$ & $\begin{array}{l}5,7 \\
6,2\end{array}$ \\
\hline C.V. (\%) & 25,12 & 8,64 & 4,97 & 13,37 & 34,76 & 19,18 & 3,00 & 19,45 & 14,19 & 24,33 & 47,08 & 31,32 & 10,85 \\
\hline
\end{tabular}

Médias seguidas de letras distintas, nas colunas, para cada fator, diferem entre si, pelo teste de Tukey, a $5 \%$. Tratamentos de adubação: $\mathrm{ADI}-12 \mathrm{~kg} \mathrm{ha}^{-1}$ de N, 90 de $\mathrm{P}_{2} \mathrm{O}_{5}$ e 30 de $\mathrm{K}_{2} \mathrm{O}$, e AD2 - $24 \mathrm{~kg}$ ha-1 de N, 180 de $\mathrm{P}_{2} \mathrm{O}_{5}$ e 60 de $\mathrm{K}_{2} \mathrm{O}$.

porém, os teores de $\mathrm{Ca}$, Mg eS, foram influenciados pelas lâminas de água. De maneira geral, houve menor acúmulo de Ca e Mg nas lâminas com menor disponibilidade de água ( $L_{1}$ e sequeiro). Esses resultados corroboram os de Ponnamperuma (1975), Stone (1985) e Carval hoJ únior (1987), querelataram que a deficiência hídrica na cultura do arroz reduz a absor ção de nutrientes. N o entanto, o teor de S foi maior no cultivo de sequeiro, talvez por causa do efeito diluição. Quanto ao N, P e K, a não-variação dos teores na matéria seca nas lâminas deágua pode ser explicada pel os bons níveis desses el ementos no solo (Quadro 1) e pela quantidade fornecida via adubação, aumentando a disponibilidade e diminuindo o efeito da menor disponibilidade hídrica na absorção desses nutrientes, apesar de a adubação não ter influenciado os teores de nutrientes.

No primeiro ano de cultivo, as quantidades de nutrientes extraídas não sofreram efeito significativo dos tratamentos (Quadro 4). No segundo ano, a adubação não influiu nas quantidades de nutrientes extraídas; no entanto, houve efeito significativo das lâminas de água. De modo geral, a extração de nutrientes (N, P, Ca, Mg e S) foi menor nos tratamentos que receberam menor quantidade de água durante o cicl o da cultura (sequeiro e $L_{1}$ ). Esse resultado depende da maior produção de matéria seca nas lâminas $L_{2}, L_{3}$ e $L_{4}$ e do efeito da menor disponibilidade de água sobre os teores de nutrientes. $\mathrm{Na}$ média dos dois anos, os tratamentos irrigados proporcionaram uma extração de nutrientes $66 \%$ maior que o tratamento de sequeiro.

Independentemente dos tratamentos utilizados, o cultivar IAC 201 apresentou, nos dois anos de cultivo, a seguinte ordem decrescente de exigência de macronutrientes no período de florescimento: $\mathrm{N}>\mathrm{K}>\mathrm{Ca}>\mathrm{Mg}>\mathrm{P}>\mathrm{S}$, bastante semelhante à observada por Gargantini \& Blanco (1965), $\mathrm{N}>\mathrm{K}>\mathrm{Ca}>\mathrm{Mg}>\mathrm{P}$, e diferente das seqüências relatadas por Fageria et al. (1997) $\mathrm{K}>\mathrm{N}>\mathrm{Ca}>$ Mg >P eCrusciol et al. (1999), para o cultivar IAC 201 no sistema de sequeiro, $\mathrm{N}>\mathrm{K}>\mathrm{Mg}>\mathrm{Ca}>\mathrm{P}>\mathrm{S}$.

A produtividade de grãos foi influenciada somente pelos tratamentos de irrigação, nos dois anos de cultivo, e na safra de 1994/95, todos os tratamentos no sistema irrigado por aspersão proporcionaram produtividades significativamente superiores às do sistema de sequeiro (Quadro 5). J á em 1995/96, tanto o tratamento de sequeiro quanto a menor lâmina de água aplicada $\left(\mathrm{L}_{1}\right)$ acarretaram produtividades inferiores às dos tratamentos com maior disponibilidade hídrica $\left(L_{2}, L_{3}\right.$ e $\left.L_{4}\right)$, em virtude da maior ocorrência de veranicos no período denovembroa março(Figura 1). Assim, a quantidade de água fornecida pela lâmina $L_{1}$ não foi suficiente para o desenvolvimento adequado da planta durante esses períodos de baixas precipitações pluviais. 
Vale ressaltar que o aumento da produtividade de grãos pela irrigação por aspersão varia entre os cultivares (Oliveira, 1994) e depende da distribuição e da quantidade de precipitação pluvial ocorrida durante o ciclo da cultura (Sant'ana, 1989).

Com relação aos teores de nutrientes nos grãos com casca, no ano agrícola de 1994/95, exceto para o $\mathrm{K}$, não houve diferença significativa entre os tratamentos. O teor de $\mathrm{K}$ foi maior nos grãos provenientes do tratamento de sequeiro em relação às lâminas $\mathrm{L}_{3} \mathrm{eL}_{4}$. Esseresultado pode ser explicado pelo efeito de diluição, já que a produtividade de grãos foi inferior no tratamento de sequeiro, enquanto os teores de nutrientes na matéria seca da parte aérea foram semelhantes entre os tratamentos. Esse mesmo raciocínio pode ser aplicado para os teores de N, P, Mg e S, que, apesar de não terem sofrido efeito significativo dos tratamentos, foram maiores nos grãos do tratamento de sequeiro.

Na safra de 1995/96, os teores de nutrientes nos grãos com casca, com exceção do N, P e Mg, foram influenciados, de forma significativa, pelas lâminas de água, porém o mesmo não foi verificado para o fator adubação. Analisando os quadros 4 e 5 , constata-se que o teor de $\mathrm{N}$ pouco variou, tanto na parte aérea, quanto nos grãos. Boa parte do $\mathrm{P}$ absorvido pelas plantas foi transl ocada para os grãos.
Quanto ao Ca, Mg, S, e principalmente o K, houve pouca transl ocação da parte aérea para os grãos.

Quanto à exportação de nutrientes (Quadro 5), houve efeito significativo dos tratamentos com relação ao N, P, K e Ca, em ambos os experimentos. Na safra de 1994/95, a exportação de N e Ca no tratamento de sequeiro foi estatisticamenteinferior à dos tratamentos irrigados por aspersão e, com relação ao $\mathrm{P}$ e o K, a diferença se deu em relação à lâmina $L_{3}$. J á em 1995/96, a exemplo do que ocorreu com a quantidade de nutriente extraída até o florescimento, também para a quantidade de nutriente exportada pelos grãos, somente o K não sofreu influência dos tratamentos. De modo geral, a irrigação por aspersão proporcionou exportação de nutrientes 55 \% maior em relação ao tratamento de sequeiro. A reduçãona exportaçãodemacronutrientes influenciada pela deficiência hídrica também foi constatada por Carvalho J únior (1987).

Os nutrientes exportados pelo arroz com casca, independentemente do tratamento estudado, obedeceram à seguinte ordem decrescente: $\mathrm{N}>\mathrm{Ca}>$ $\mathrm{K}>\mathrm{P}>\mathrm{Mg}>\mathrm{S}$ (Quadro 5), que é bem diferente da relatada por Barbosa Filho (1987), como da de Fornasieri Filho\& Fornasieri (1993). Essa divergência de resultados pode ser explicada pelas diferenças varietais, manejo da cultura, níveis e quantidades de nutrientes no solo aplicadas por meio da adubação.

Quadro 5. Produtividade, teores e quantidades de macronutrientes exportados pelos grãos de arroz, cv. IAC 201, de acordo com diferentes lâminas de água e doses de adubação mineral. Selvíria (MS)

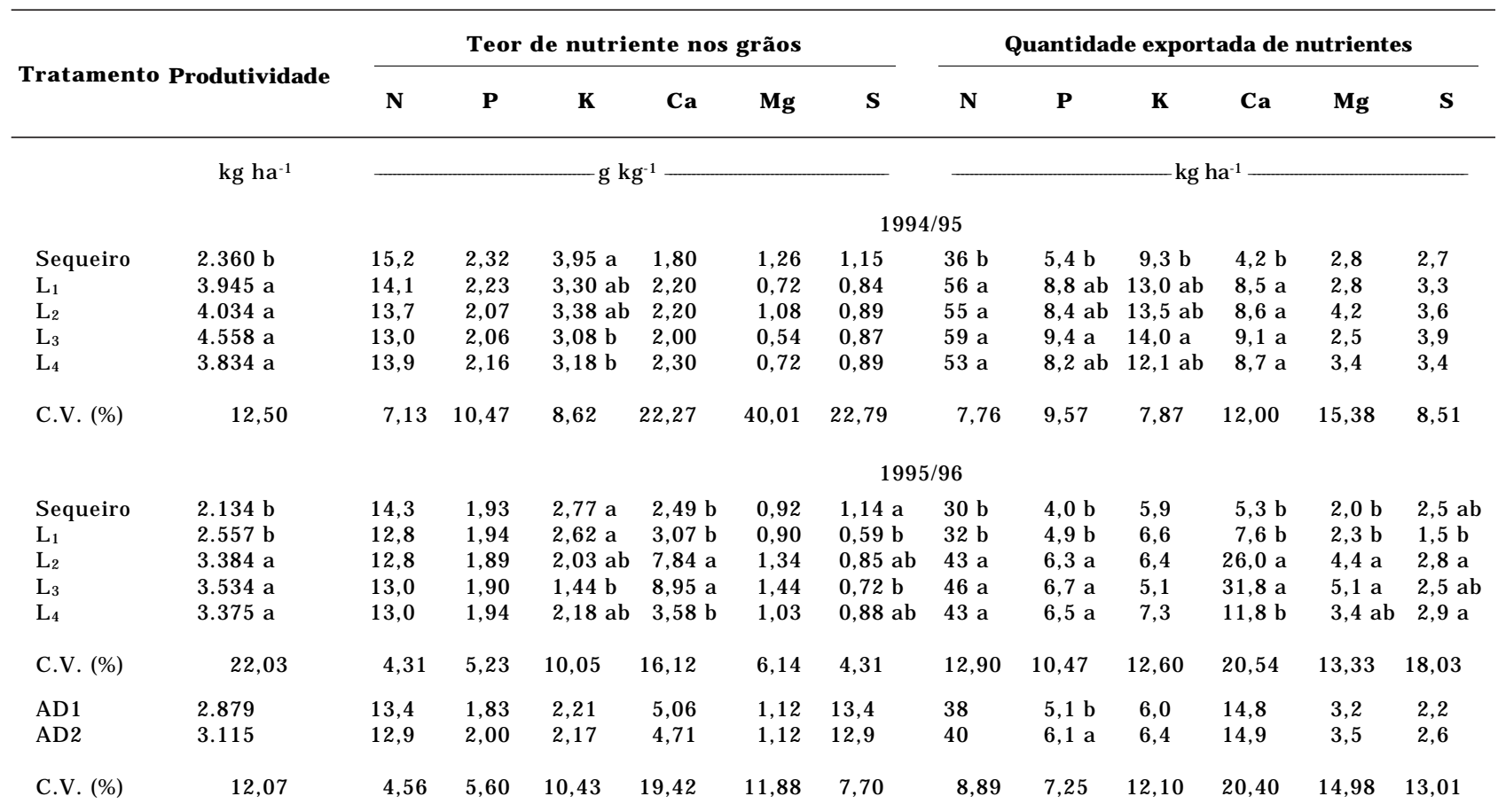

Médias seguidas de letras distintas, nas colunas, para cada fator, diferem entre si, pelo teste de Tukey, a $5 \%$. Tratamentos de adubação: ADI - $12 \mathrm{~kg} \mathrm{ha}^{-1}$ de N, 90 de $\mathrm{P}_{2} \mathrm{O}_{5}$ e 30 de $\mathrm{K}_{2} \mathrm{O}$, e AD2 - 24 kg ha-1 de N, 180 de $\mathrm{P}_{2} \mathrm{O}_{5}$ e 60 de $\mathrm{K}_{2} \mathrm{O}$. 


\section{CONCLUSÕES}

1. A menor disponi bilidade deágua durantea fase vegetativa e reprodutiva do arroz cv. IAC 201 reduz sua produção dematéria seca eos teores denutrientes da parteaérea, bem como a quanti dade dos nutrientes extraídos pelas plantas até o florescimento.

2. O sistema de irrigação por aspersão, independentemente da lâmina de água aplicada, proporcionou maior produtividade de grãos do arroz I AC 201 e exportação de nutrientes.

3. Em solos com teores adequados de nutrientes para o sistema de sequeiro, não há resposta ao aumento da adubação mineral pel o arroz no sistema irrigado por aspersão, apesar da maior absorção de nutrientes.

\section{LITE RATURA CITADA}

BARBOSA FILHO, M.P. Nutrição eadubação do arroz (sequeiro eirrigado). Piracicaba, Associação Brasileira para Pesquisa da Potassa e do F osfato, 1987. 129p. (Boletim Técnico, 9)

BATAGLIA, O.C.; FURLANI, A.M.C.; TEIXEIRA, J .P.F.; FURLANI, P.R. \& GALLO, J.R. Métodos de análises químicas de plantas. Campinas, Instituto Agronômico de Campinas, 1983. 48p.

CARVALHO J ÚNIOR, A.G. Efeito da adubação potássica em cultivares de arroz (Oryza sativa L.) de sequeiro sob déficit hídrico, em solos sob cerrados. Lavras, Escola Superior de Agricultura de Lavras, 1987. 165p. (Tese de Mestrado)

CRUSCIOL, C.A.C.; MACHADO, J .R.; ARF, O. \& RODRIGUES, R.A.F. Produtividade do arroz irrigado por aspersão em função do espaçamento e da densidade de semeadura. Pesq. Agropec. Bras., 35:1093-1100, 2000.

CRUSCIOL, C.A.C; MACHADO, J .R.; ARF, O. \& RODRIGUES, R.A.F. Matéria seca e absorção de nutrientes em função do espaçamento e da densidade de semeadura em arroz de terra alta. Sci. Agric., 56:63-70, 1999.

DOORENBOS, J . \& PRUITT, W.O. Las necessidades de agua de los cultivos. Roma, FAO, 1976. 194p. (Estudos FAO: Riego e Drenaje, 24)

EMPRESA BRASILEIRA DE PESQUISA AGROPECUÁRIA EMBRPA. Sistema Brasileiro de Classificação dos Solos. Rio de J aneiro, 1999. 41p.

FAGERIA, N.K.; BALIGAR, V.C. \& J ONES, C.A. Growth and mineral nutrition of field crops. 2. ed. New York, Marcel Dekker, 1997. 453p.

FAGERIA, N.K.; SANT'ANA, E.P. \& MORAIS, O.P. Resposta de genótipos de arroz de sequeiro favorecido à fertilidade do solo. Pesq. Agropec. Bras., 30:1155-1161, 1995.

FORNASIERI FILHO, D. \& FORNASIERI, J.L. Manual da cultura do arroz. J aboticabal, FUNEP, 1993. 221p.

GARGANTINI, H. \& BLANCO, H.G. Absorção de nutriente pela cultura do arroz, Bragantia, 24:515-528, 1965.
GIUDICE, R.M.; HAAG, H.P.; THIÉBAUT, J .T.L. \& DECHEN, A.R. Absorção cumulativa de nutrientes minerais em duas variedades de arroz (Oryza sativa L.), cultivadas em três diferentes níveis de disponibilidade d'água. Campinas, Fundação Cargill, 1983. 78p.

OLIVEIRA, G.S. Efeito de densidades de semeadura no desenvolvimento de cultivares de arroz (Oryza sativa L.) em condições de sequeiro e irrigado por aspersão. Il ha Solteira, Universidade Estadual Paulista, 1994. 41p. (Monografia de Graduação)

PONNAMPERUMA, F.N. Growth-limiting factors of aerobic soils. In: INTERNATIONAL RICE RESEARCH INSTITUTE, Los Baños, Filipinas. Major research in upland rice. Los Baños, 1975. p.40-43.

PRASERTSAK, A. \& FUKAI, S. Nitrogen availability and water stress interaction on rice growth and yield. Field Crop Res., 52:249-260, 1997.

RAIJ , B. van \& QUAGGIO, J.A. Métodos de análise de solo para fins de fertilidade. Campinas, Instituto Agronômico de Campinas, 1983. 85p. (Boletim Técnico, 81)

RAIJ , B. van; CANTARELA, H.; QUAGGIO, J .A. \& FURLANI, A.M.C. Recomendações de adubação e calagem para o estado de São Paulo. 2.ed. Campinas, Instituto Agronômico e Fundação IAC, 1996. 285p. (Boletim técnico, 100)

RAIJ , B. van; SILVA, N.M.; BATAGLIA, O.C.; QUAGGIO, J .A.; HIROCE, R.; CANTARELLA, H.; BELLINAZZI J ÚNIOR, R.; DECHEN, A.R. \& TRANI, P.E. Recomendações de adubação e cal agem para o estado de São Paulo. Campinas, Instituto Agronômi co de Campinas eSAAESP, 1985. 107p. (Boletim técnico, 100)

REICHARDT, K. Relações solo-água-planta para algumas culturas. In: REICHARDT, K. A água em sistemas agrícolas. São Paulo, Manole, 1987. p.157-71.

SANT'ANA, E.P. Cultivo de arroz irrigado por aspersão. Inf. Agropec., 14:71-5, 1989.

SANTOS, A.B.; STONE, L.F.; FAGERIA, N.K.; PRABHU, A.S.; MAH, M.G.C.; AQUINO, A.R.L.; AJIMURA, G.M.; BARBOSA FILHO, M.P.; ZIMMERMANN, F.J.P.; CARVALHO,J .R.P.; OLIVEIRA, A.B. \& SILVEIRA FILHO, A. Efeito do conjunto de técnicas aplicadas ao sistema de produção do arroz de sequeiro. Pesq. Agropec. Bras., 17:835-845, 1982.

SÃO PAULO (Estado). Secretaria de Agricultura e Abastecimento. Coordenadoria da Pesquisa Agropecuária. Instituto Agronômico. Agulhinha de Sequeiro: IAC 201. Campinas, 1992. não paginado (Cultivar de arroz para o estado de São Paulo)

STONE, L.F . Absorção deP, K, Mg, Ca eS por arroz, influenciada pela deficiência hídrica, vermiculita e cultivar. Pesq. Agropec. Bras., 20:1251-1258, 1985.

STONE, L.F.; LIBARDI, P.L. \& REICHARDT, K. Deficiência hídrica, vermiculita e cultivares. Pesq. Agropec. Bras., 19:695-707, 1984.

TANGUILIG, V.C.; YAMBAO, E.B.; O'TOOLE, J.C. \& DE DATTA, S.K. Water stress effects on leaf el ongation, leaf water potential, transpiration, and nutrient uptake of rice, maize, and soybean. Plant Soil, 103:155-168, 1987. 